\title{
Assessment of Empiric Vancomycin Regimen in the Neonatal Intensive Care Unit
}

\author{
Ruthdol Ywaya and Brandi Newby
}

\begin{abstract}
Background: Vancomycin is used to treat serious gram-positive infections in neonates. Currently, there is no consensus on the preferred empiric dosing regimen or target trough vancomycin levels for neonates. The current Fraser Health empiric dosing regimen, implemented in 2010, was designed to achieve target trough levels of 5 to $15 \mathrm{mg} / \mathrm{L}$.

Objectives: To determine the percentage of neonates receiving vancomycin in whom target trough levels of 5 to $15 \mathrm{mg} / \mathrm{L}$ were achieved, to identify the times to negative culture result and clinical resolution, and to determine the incidence of nephrotoxicity.
\end{abstract}

Methods: A chart review was completed for patients who had received vancomycin in the neonatal intensive care unit of either Surrey Memorial Hospital or Royal Columbian Hospital from June 2012 to May 2017 and for whom at least 1 interpretable vancomycin level was available.

Results: A total of 87 vancomycin encounters (in 78 neonates) were identified in which the drug had been given according to the Fraser Health empiric dosing regimen. Target trough vancomycin level (5 to $15 \mathrm{mg} / \mathrm{L}$ ) was achieved in $75 \%$ of these encounters. The mean times to negative culture result and clinical resolution were 5 and 6 days, respectively. There was no statistically significant correlation between vancomycin level and time to clinical resolution $\left(r_{s}=0.366, p=0.072\right)$. Among cases in which the trough vancomycin level exceeded $15 \mathrm{mg} / \mathrm{L}$, the incidence of nephrotoxicity was $22 \%(4 / 18)$.

Conclusions: The current Fraser Health empiric dosing regimen for vancomycin achieved target trough levels of the drug for most neonates in this study. Targeting trough levels less than $15 \mathrm{mg} / \mathrm{L}$ when appropriate to the infection type may limit nephrotoxicity associated with vancomycin in neonates. Further studies are needed to evaluate the clinical significance of various vancomycin levels.

Keywords: neonatal intensive care unit, newborn, vancomycin, pharmacokinetics, clinical effectiveness

\section{RÉSUMÉ}

Contexte : La vancomycine est utilisée dans le traitement d'infections graves à bactéries à Gram positif chez le nouveau-né. Il n'y a pour l'instant pas de consensus quant à la posologie empirique ou aux concentrations minimales visées de vancomycine à privilégier chez le nouveau-né. La posologie empirique actuelle de la Fraser Health, instaurée en 2010, visait des concentrations minimales de 5 à $15 \mathrm{mg} / \mathrm{L}$.

Objectifs : Déterminer le pourcentage de nouveau-nés ayant reçu les concentrations minimales visées de 5 à $15 \mathrm{mg} / \mathrm{L}$ de vancomycine, établir le temps nécessaire à l'obtention d'un résultat de culture négatif et celui nécessaire à la disparition clinique des symptômes et déterminer l'incidence de la néphrotoxicité.

Méthodes : Les investigateurs ont analysé des dossiers de patients ayant reçu de la vancomycine pendant leur séjour à l'unité de soins intensifs néonatals du Surrey Memorial Hospital ou du Royal Columbian Hospital entre juin 2012 et mai 2017, qui mentionnaient au moins une concentration de vancomycine interprétable.

Résultats : Ils ont répertorié 87 traitements de vancomycine (chez 78 nouveau-nés) administrés selon la posologie empirique de la Fraser Health. Les concentrations minimales visées de 5 à $15 \mathrm{mg} / \mathrm{L}$ ont été atteintes dans $75 \%$ de ces traitements. Le temps moyen nécessaire à l'obtention d'un résultat de culture négatif ou à la disparition clinique des symptômes était respectivement de cinq et de six jours. Aucune corrélation statistiquement significative entre les concentrations de vancomycine et le temps nécessaire à la disparition clinique des symptômes n'a été relevée $\left(r_{s}=0,366\right.$, $p=0,072)$. Parmi les cas où les concentrations minimales de vancomycine dépassaient $15 \mathrm{mg} / \mathrm{L}$, l'incidence de néphrotoxicité était de $22 \%$ (4/18).

Conclusions : La posologie empirique de vancomycine actuellement en place à la Fraser Health a permis d'atteindre les concentrations minimales visées de médicament pour la plupart des nouveau-nés de la présente étude. Cibler des concentrations minimales de moins de $15 \mathrm{mg} / \mathrm{L}$ lorsque cela est pertinent en fonction du type d'infection pourrait limiter le nombre de cas de néphrotoxicité associés à la vancomycine chez les nouveau-nés. De plus amples études sont nécessaires pour évaluer la portée clinique de différentes concentrations de vancomycine.

Mots clés : unité de soins intensifs néonatals, nouveau-né, vancomycine, pharmacocinétique, efficacité clinique 


\section{INTRODUCTION}

$\mathrm{I}_{\mathrm{u}}^{\mathrm{n}}$ the neonatal intensive care unit (NICU), vancomycin is used to treat serious gram-positive infections such as sepsis, meningitis, pneumonia, skin and soft-tissue infections, necrotizing enterocolitis, and osteomyelitis. The predominant gram-positive organisms of late-onset infections in the NICU are coagulasenegative Staphylococcus and Staphylococcus aureus. ${ }^{1,2}$ These organisms have been shown to be sensitive to vancomycin when the minimum inhibitory concentration (MIC) is $2 \mathrm{mg} / \mathrm{L}$ or less. ${ }^{3}$

Time above the MIC or ratio of area under the curve to MIC has been used to assess vancomycin efficacy in adults, but there is lack of evidence for use of these measures in neonates. Vancomycin has been shown to exert bactericidal activity against Staphylococcus when the unbound levels are 4 to 5 times the MIC. ${ }^{4-7}$ Because vancomycin is about $50 \%$ protein-bound, this translates to target levels of 4 to $5 \mathrm{mg} / \mathrm{L}$ for MIC of $0.5 \mathrm{mg} / \mathrm{L}$, 8 to $10 \mathrm{mg} / \mathrm{L}$ for MIC of $1 \mathrm{mg} / \mathrm{L}$, and 15 to $20 \mathrm{mg} / \mathrm{L}$ for MIC of $2 \mathrm{mg} / \mathrm{L}$.

Other factors, including the type, location, and severity of infection, should also be considered when determining the target vancomycin level. For patients with infections at sites that are difficult to penetrate, such as the lungs or brain, adult guidelines suggest targeting higher serum levels, specifically 15 to $20 \mathrm{mg} / \mathrm{L}$, regardless of MIC, to ensure adequate penetration of the vancomycin. ${ }^{6,8}$ However, for less serious infections, such as uncomplicated infections of skin or soft tissue or infections of the urinary tract, lower targets may be adequate because of excellent clinical response rates with traditional vancomycin dosing. ${ }^{8}$

Pharmacokinetic data show that trough levels of 5 to $10 \mathrm{mg} / \mathrm{L}$ are sufficient to resolve infections with coagulasenegative Staphylococcus in neonates. By contrast, in adults, higher trough levels (10 to $20 \mathrm{mg} / \mathrm{L}$ ) are associated with increased efficacy relative to lower trough levels $(<10 \mathrm{mg} / \mathrm{L})$, particularly in patients with methicillin-resistant Staphylococcus aureus. ${ }^{6,9,10}$ However, in vitro studies have shown no difference in efficacy with concentrations above the MIC. ${ }^{11}$ In addition, prolonged exposure to serum levels close to the MIC has been associated with increased risk of resistance. ${ }^{12}$
Currently, there is no consensus in the literature regarding the optimal vancomycin dosing regimen or target trough concentrations that are associated with better clinical outcomes in neonates. Some organizations have adopted the target levels for adults without evaluating the potential need for higher targets or the risks associated with those adult targets in the neonatal population. It is also not clear whether the recommended adult target levels are required to achieve desired clinical outcomes in neonates. A study by Barriere and others ${ }^{13}$ suggested that higher vancomycin trough levels do not improve the clinical response but likely increase the incidence of nephrotoxicity. Relative to adults, neonates have a larger extracellular fluid volume, which could influence the distribution of vancomycin. Additionally, neonates have lower renal elimination and protein binding than adults, and vancomycin efficacy may be influenced by these pharmacokinetic differences. ${ }^{10}$

Following a local neonatal review in 2002 (unpublished data), the Fraser Health empiric vancomycin regimen was changed at one site in the health authority, and the revised neonatal regimen was then implemented regionally in 2010 (Table 1). This regimen was designed to generate trough levels of 5 to $15 \mathrm{mg} / \mathrm{L}$ for the majority of NICU patients. The current study was undertaken to evaluate the empiric regimen that had been in effect since 2010 , to determine the percentage of neonates in whom target trough vancomycin levels of 5 to $15 \mathrm{mg} / \mathrm{L}$ were achieved, to identify the times to negative culture result and clinical resolution, and to determine the incidence of nephrotoxicity.

\section{METHODS}

Ethics approval for this study was obtained from the Fraser Health Research Ethics Board.

For this chart review, the pharmacy department of Surrey Memorial Hospital generated a list of neonates who received vancomycin in the NICU of either Surrey Memorial Hospital or the Royal Columbian Hospital between June 1, 2012, and May 31, 2017. Any neonate on this list for whom an interpretable vancomycin level was available and whose electronic chart was accessible was included in the study. An interpretable vancomycin

Table 1. Current Fraser Health Empiric Dosing Regimen for Vancomycin

\begin{tabular}{llll} 
Postmenstrual Age & Vancomycin Dosage & $\begin{array}{c}\text { No. of Patient Encounters } \\
\text { by Dose }(\boldsymbol{n}=\mathbf{8 7})\end{array}$ & $\begin{array}{c}\text { Mean Vancomycin Level } \\
\text { (Range) (mg/L) }\end{array}$ \\
\hline$<30$ weeks & $10 \mathrm{mg} / \mathrm{kg} \mathrm{IV} \mathrm{q12h}$ & $10 \mathrm{mg} / \mathrm{kg}: n=42$ & 11.0 (ND to 18.1) \\
\hline$\geq 30$ weeks, $0-7$ days & $10-15 \mathrm{mg} / \mathrm{kg} \mathrm{IV} \mathrm{q12h}$ & $10 \mathrm{mg} / \mathrm{kg}: n=1$ & 11.9 (NA) \\
of life & & $11 \mathrm{mg} / \mathrm{kg}: n=1$ & 12.2 (NA) \\
& & $15 \mathrm{mg} / \mathrm{kg}: n=3$ & 16.2 (8.5 to 29.5) \\
\hline$\geq 30$ weeks, $>$ 7 days & $10-15 \mathrm{mg} / \mathrm{kg} \mathrm{IV} \mathrm{q8h}$ & $10 \mathrm{mg} / \mathrm{kg}: n=18$ & 11.2 (ND to 21.3) \\
of life & & $11 \mathrm{mg} / \mathrm{kg}: n=4$ & 11.9 (10.2 to 15.4) \\
& & $12 \mathrm{mg} / \mathrm{kg}: n=3$ & 9.9 (7.5 to 12.3) \\
& $13 \mathrm{mg} / \mathrm{kg}: n=7$ & 14.9 (8.6 to 21.2) \\
& $14 \mathrm{mg} / \mathrm{kg}: n=3$ & $13.6(10.1$ to 19.1) \\
\hline
\end{tabular}

$\overline{\mathrm{NA}}=$ not applicable, ND = not detectable. 
level was defined by a serum sample for measurement of trough level drawn within $60 \mathrm{~min}$ before the third dose (or a later dose); alternatively, if 2 measurements had been done for a given patient, the serum trough level could be calculated from the 2 results, as described below. Patients were excluded if the postmenstrual age was greater than 45 weeks, if there was no electronic chart, if no vancomycin level had been recorded, or if vancomycin measurements had been inappropriately obtained.

For this study, the data collected included the following information about the patient; gestational age, birth weight, postmenstrual age, day of life and weight when vancomycin was started, baseline feeding status, urine output, concurrent vasopressor use, concurrent antibiotic use as well as antibiotic use within $48 \mathrm{~h}$ before initiation of vancomycin therapy, and infection type. In cases with a positive culture result, the MIC of the infective organism was recorded, if available. The vancomycin regimen, duration of therapy, and serum levels of vancomycin were also recorded. For patients who had received more than 1 course of vancomycin, all courses within the study period were included in the analysis, entered as separate encounters. For patients with multiple samples drawn during a single vancomycin course, only the first measured level obtained with the empiric regimen was assessed.

In cases where a serum trough level within $60 \mathrm{~min}$ of next dose was not available, but 2 interpretable levels had been obtained, pharmacokinetic calculations were used. The individual elimination rate constant $(\mathrm{K})$ and extrapolated trough level were calculated according to the 2-point modified Sawchuk-Zaske method. ${ }^{14}$

Time to negative culture result was determined by analyzing data for patients with an initial positive culture result and then a subsequent repeat culture result; this analysis included only patients with an indication that required vancomycin therapy. Repeat culture was performed at the discretion of the attending physician. Results from repeat culture of endotracheal tube samples were excluded because of possible colonization. The time to negative culture result was defined as the number of days between initiation of vancomycin and the first negative result.

For clinical outcomes, the following information was collected: need for and type of respiratory support; oxygen requirements; recorded instances of apnea, bradycardia, or desaturation; vasopressor use; temperature of patient and isolette; feeding volume; any medical imaging reports; and complete blood counts. Baseline data were collected for the patients for the day before initiation of vancomycin for comparison with data collected throughout the vancomycin course. Clinical resolution was defined as a return to baseline clinical status. For determining whether patients had experienced nephrotoxicity, the following data were collected: serum creatinine, urine output, and concomitant nephrotoxic medications. Neonatal nephrotoxicity was defined on the basis of either of the following criteria: increase in serum creatinine of at least $26.5 \mu \mathrm{mol} / \mathrm{L}$ or at least $50 \% .^{15}$
Descriptive statistics were used to analyze the data in this study. The Spearman rho correlation coefficient was calculated to describe the relation between vancomycin level and time to clinical resolution. For this 2 -sided test, $p<0.05$ was deemed to represent statistical significance.

\section{RESULTS}

In total, $147 \mathrm{NICU}$ patients received vancomycin during the study period (Figure 1), of whom 78 were included in the analysis and 69 were excluded. Several of the patients received more than 1 course of vancomycin therapy; as such, there were 87 encounters in which neonates received vancomycin according to the Fraser Health empiric regimen.

For the 87 patient encounters, the mean postmenstrual age was 30 weeks when vancomycin was started (Table 2). The most common infections that required vancomycin were coagulasenegative Staphylococcus bacteremia or sepsis (22 [25\%]), suspected sepsis (23 [26\%]), and necrotizing enterocolitis (19 [22\%]). There were no cases of methicillin-resistant Staphylococcus aureus. For 29 cultures, the MIC was reported. Of these, $6(21 \%)$ had MIC less than or equal to $0.5 \mathrm{mg} / \mathrm{L}, 16(55 \%)$ had MIC of $1 \mathrm{mg} / \mathrm{L}, 7$ (24\%) had MIC of $2 \mathrm{mg} / \mathrm{L}$, and none had MIC above $2 \mathrm{mg} / \mathrm{L}$.

Among the 87 encounters, 43 involved an empiric vancomycin dosage of $10 \mathrm{mg} / \mathrm{kg}$ IV q12h, 1 involved a dosage of $11 \mathrm{mg} / \mathrm{kg}$ IV q12h, 3 involved a dosage of $15 \mathrm{mg} / \mathrm{kg}$ IV q12h, 18 involved a dosage of $10 \mathrm{mg} / \mathrm{kg}$ IV q $8 \mathrm{~h}, 5$ involved a dosage of $15 \mathrm{mg} / \mathrm{kg}$ IV q8h, and 17 involved a dosage range of 11 to 14 $\mathrm{mg} / \mathrm{kg}$ IV q8h (Table 1 ). The average duration of vancomycin therapy was 7 days. We did not evaluate the reasons why patients required prolonged courses of therapy, because all patients in this study had received antibiotics for the recommended duration for the presumed diagnoses.

Data for vancomycin levels were interpretable for all but 1 of the 87 patient encounters; for the sole exception, the pharmacokinetic calculation was performed. With the Fraser Health empiric regimen, 65 (75\%) of the 87 vancomycin trough levels were within the target range (5 to $15 \mathrm{mg} / \mathrm{L})$, and $14(16 \%)$ were between 15.1 and $20 \mathrm{mg} / \mathrm{L}$, for a total of 79 (91\%) between 5 and $20 \mathrm{mg} / \mathrm{L}$ (Figure 2); 48 (55\%) of the 87 measured trough levels were between 10 and $20 \mathrm{mg} / \mathrm{L}$.

A positive culture result was obtained for $36(41 \%)$ of the 87 encounters (Figure 3). For determination of time to negative culture result, 21 encounters were included. The other 15 encounters with an initially positive culture result were excluded for the following reasons: endotracheal tube sample $(n=5)$, no indication for vancomycin $(n=4)$, and no repeat culture performed $(n=6)$. The mean time to repeat culture and the time to negative culture result were 4 and 5 days, respectively (range 1 to 12 days for both). For 7 of the 21 encounters with repeat culture, the repeat result was positive; for all of these, negative results were eventually obtained on subsequent repeat culture. 


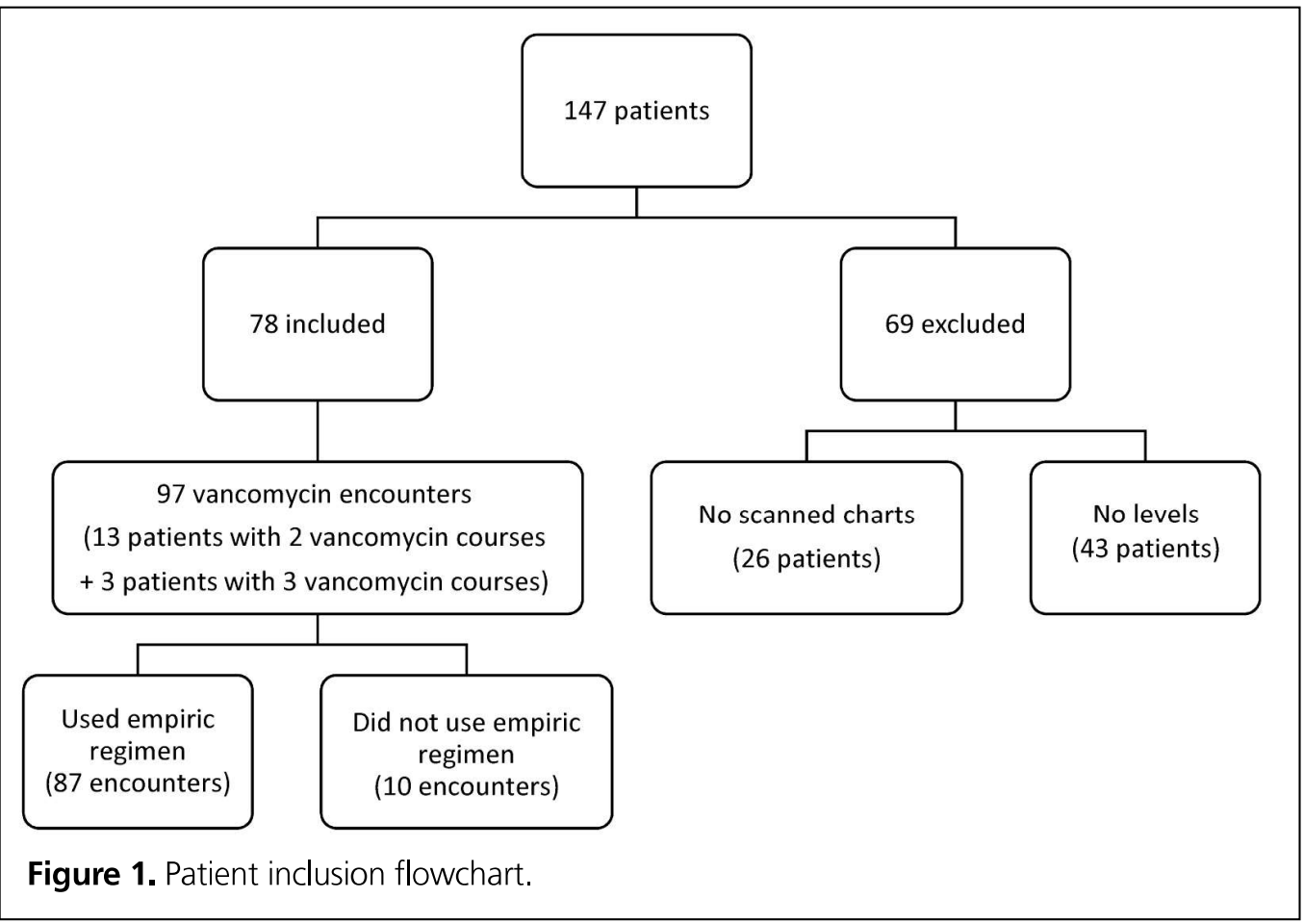

For determination of clinical resolution, 4 encounters were excluded because there was no indication for vancomycin. No change from baseline clinical status was documented for 58 (70\%) of the 83 vancomycin encounters included in this analysis. The other 25 encounters $(30 \%)$ had a change from baseline clinical status followed by an eventual return to baseline status, with time to clinical resolution of about 6 days (range 2 to 17 days). For these 25 patients with a change in clinical status from baseline, there was no statistically significant correlation between vancomycin trough level and time to clinical resolution $\left(r_{s}=0.366, p=0.072\right)$ (Figure 4).

There were a total of 26 encounters in which concurrent nephrotoxic medications were administered, specifically indomethacin, gentamicin, or furosemide. For 17 of these encounters, the vancomycin level was less than $15 \mathrm{mg} / \mathrm{L}$. Neonatal nephrotoxicity occurred in $4(5 \%)$ of the 78 patients included in this study. The mean time to nephrotoxicity from initiation of vancomycin was 3 days (range 1 to 5 days) (Table 3 ). For 3 of the 4 patients with nephrotoxicity, gentamicin was the only concomitant nephrotoxic medication administered. One of the patients receiving gentamicin also experienced septic shock requiring vasopressors. The incidence of nephrotoxicity was $22 \%(4 / 18)$ among patients with vancomycin level above $15 \mathrm{mg} / \mathrm{L}$; none of the 60 patients with vancomycin level of $15 \mathrm{mg} / \mathrm{L}$ or below experienced nephrotoxicity.

\section{DISCUSSION}

In this study, the current Fraser Health empiric vancomycin regimen led to vancomycin trough levels between 5 and $15 \mathrm{mg} / \mathrm{L}$ for $75 \%$ of patient encounters, with $91 \%$ of encounters having trough levels that fell between 5 and $20 \mathrm{mg} / \mathrm{L}$. Given the broad range of neonates (postmenstrual age 24 to 42 weeks) included in this study and the anticipated interpatient variability, the empiric regimen generated acceptable vancomycin trough levels

\section{Table 2. Patient Characteristics}

\begin{tabular}{|c|c|c|}
\hline Characteristic & & $\begin{array}{l}\text { in (Range) or } \\
\text { lo. }(\%) \text { of } \\
\text { icounters* }\end{array}$ \\
\hline Postmenstrual age (weeks) & 30 & $(24-42)$ \\
\hline Days of life & 17 & $(1-68)$ \\
\hline Birth weight (kg) & 1 & $(0.38-4.25)$ \\
\hline Weight at initiation of vancomycin $(\mathrm{kg})$ & 1.2 & $(0.44-4.25)$ \\
\hline $\begin{array}{l}\text { Urine output at initiation of vancomycin } \\
\text { (mL/kg per hour) }\end{array}$ & 3 & (1.5 to 6.2$)$ \\
\hline NPO status & 16 & (18) \\
\hline Vasopressor therapy & 2 & $(2)$ \\
\hline Received antibiotics $48 \mathrm{~h}$ prior & 38 & (44) \\
\hline Infections & & \\
\hline CONS bacteremia/sepsis & 22 & (25) \\
\hline Suspected sepsis & 23 & (26) \\
\hline Necrotizing enterocolitis & 19 & $(22)$ \\
\hline Ventilator-associated pneumonia & 13 & (15) \\
\hline Cellulitis & 6 & $(7)$ \\
\hline $\begin{array}{l}\text { Other bacteremia (MSSA, Bacillus } \\
\text { cereus, group B Streptococcus) }\end{array}$ & 4 & (5) \\
\hline $\begin{array}{l}\text { CONS = coagulase-negative Staphyloco } \\
\text { sensitive Staphylococcus aureus, NPO = } \\
\text { * Mean values are based on } 78 \text { unique p } \\
\text { more than } 1 \text { course of therapy. Data for } \\
\text { are based on a denominator of } 87 \text { enco } \\
\text { representing an individual course of van }\end{array}$ & 8 & $\begin{array}{l}=\text { methicillin- } \\
\text { nouth. } \\
\text { e of whom had } \\
\text { of encounters } \\
\text { each encounter } \\
\text { rapy. }\end{array}$ \\
\hline
\end{tabular}




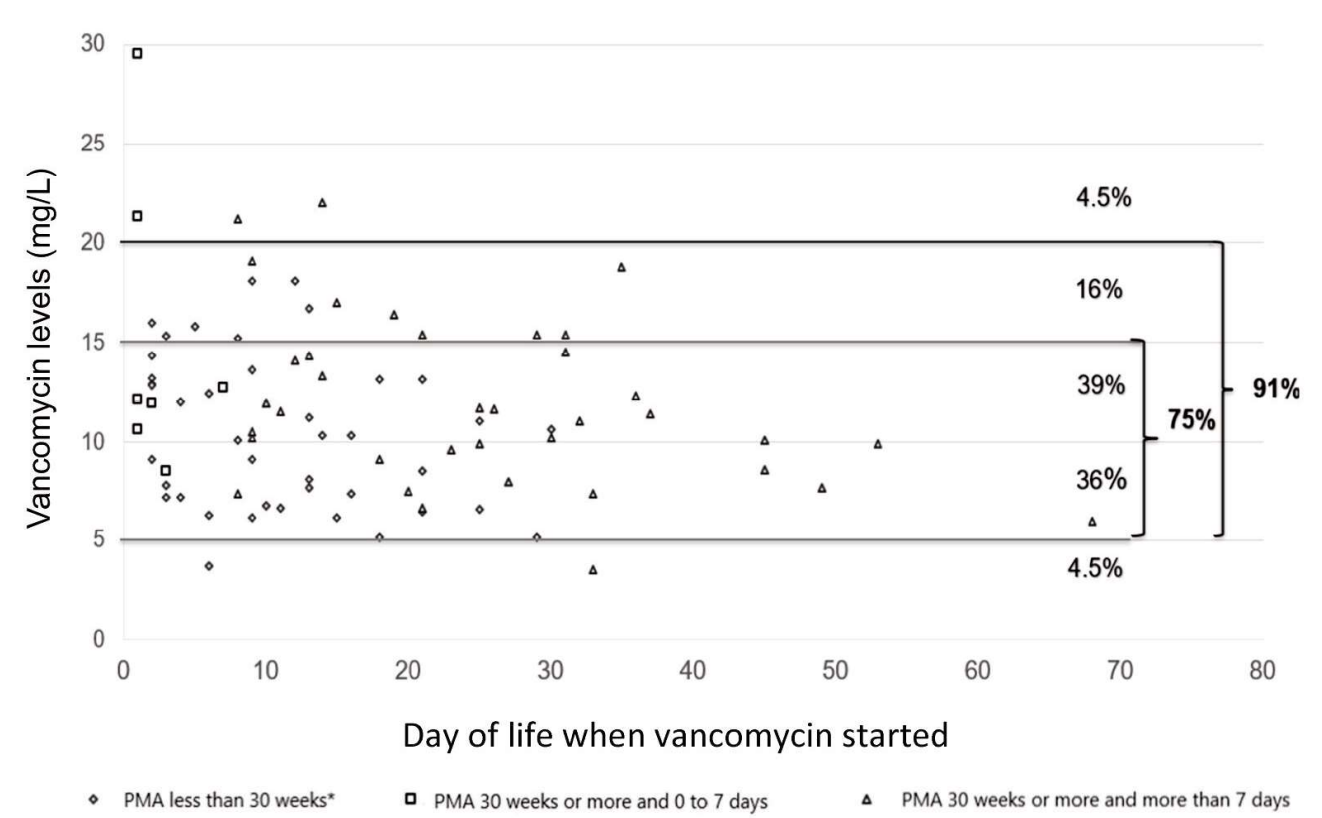

Figure 2. Scatter plot of vancomycin levels with current empiric regimen. For 2 patients, the vancomycin level was undetectable and data are therefore not shown in the scatter plot.

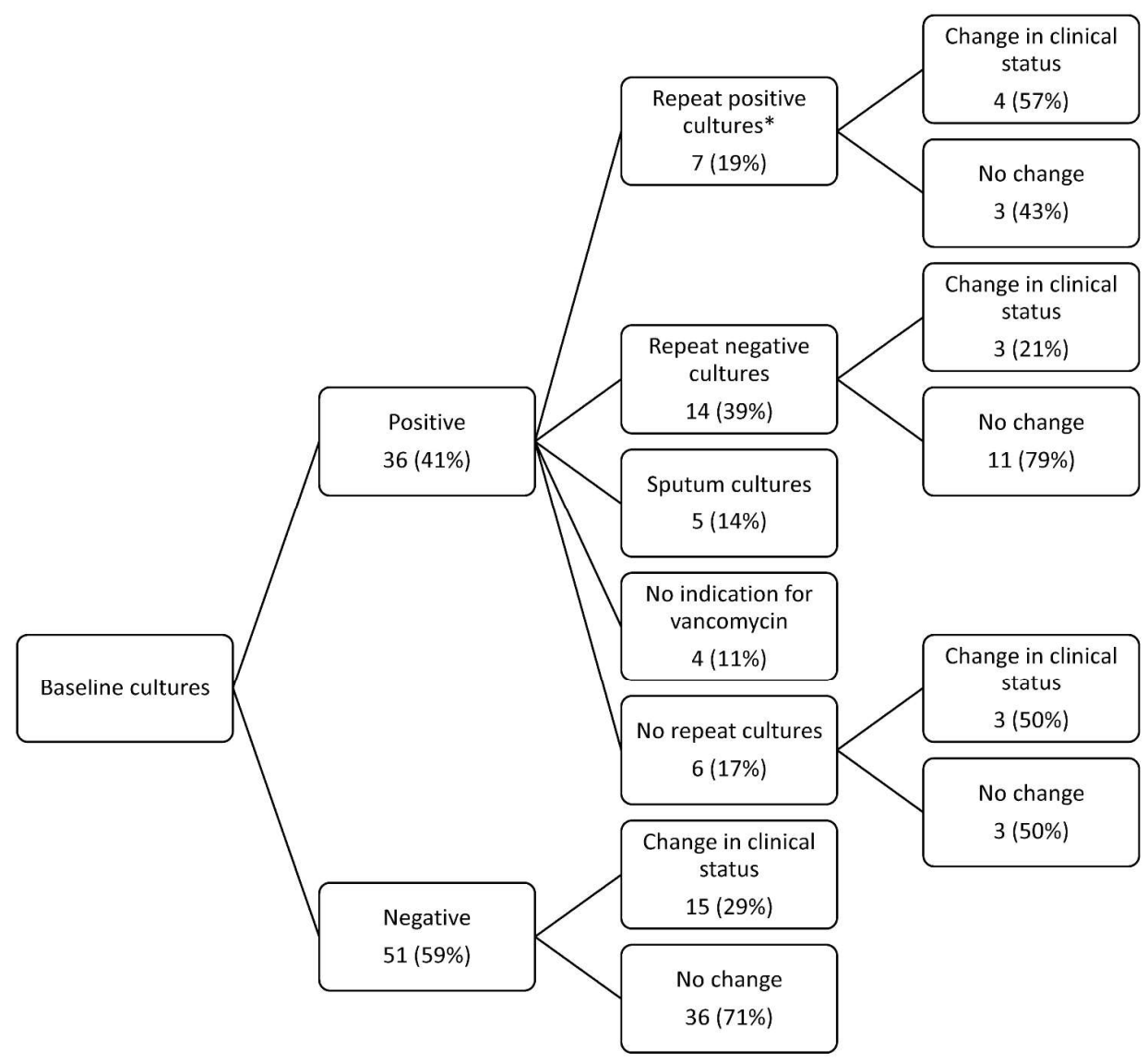

Figure 3. Culture results and clinical status. *All samples with repeat culture (following positive results on initial testing) were negative on subsequent culture. 


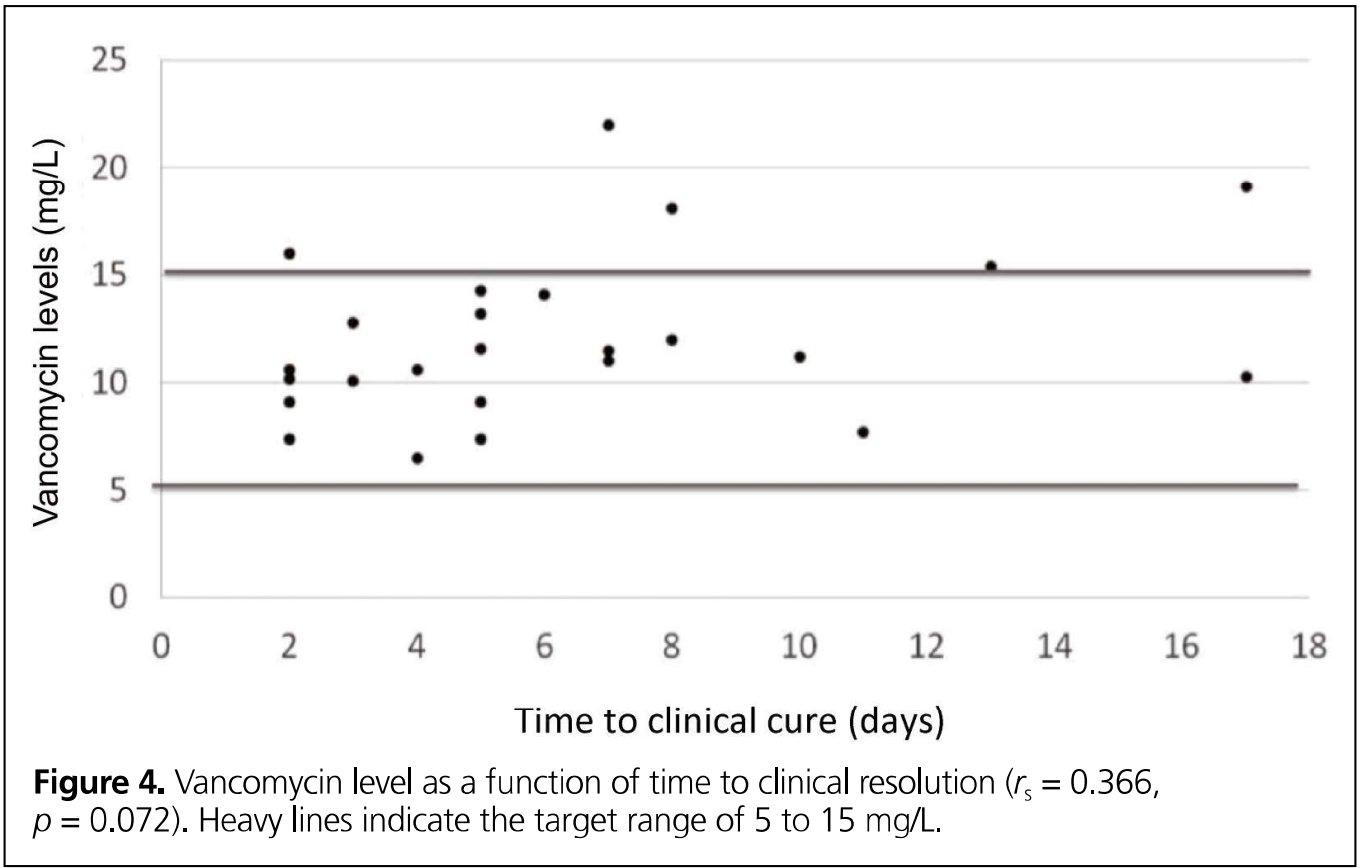

Table 3. Characteristics of Patients with Nephrotoxicity $(n=4)$

\begin{tabular}{|c|c|c|c|c|c|c|c|}
\hline PMA (weeks) & $\begin{array}{l}\text { Day of Life } \\
\text { when } \\
\text { Vancomycin } \\
\text { Started }\end{array}$ & $\begin{array}{l}\text { Day of } \\
\text { Life when } \\
\text { Nephrotoxicity } \\
\text { Documented }\end{array}$ & $\begin{array}{c}\text { Urine } \\
\text { Output* } \\
\text { (mL/kg/h) }\end{array}$ & $\mathrm{SCr}(\mu \mathrm{mol} / \mathrm{L})$ & $\begin{array}{c}\text { Increase } \\
\text { in } \mathrm{SCr}\end{array}$ & $\begin{array}{c}\text { Vancomycin } \\
\text { Level } \\
\text { (mg/L) }\end{array}$ & $\begin{array}{l}\text { Concomitant } \\
\text { Nephrotoxins }\end{array}$ \\
\hline $25+1$ & 10 & 15 & 2.9 & $74 \rightarrow 130$ & $76 \%$ & $13.6 \rightarrow 22.4$ & Yes \\
\hline $27+4$ & 13 & 14 & 2.2 & $74 \rightarrow 126$ & $70 \%$ & 18.1 & Yes \\
\hline $28+4$ & 3 & 7 & 0.58 & $40 \rightarrow 68$ & $70 \%$ & 15.3 & No \\
\hline $34+1+$ & 1 & 4 & 0 & $107 \rightarrow 168$ & $57 \%$ & 21 & Yes \\
\hline
\end{tabular}

PMA = postmenstrual age, $\mathrm{SCr}=$ serum creatinine.

*Lowest documented urine output during treatment.

tPatient had septic shock requiring vasopressors.

for a high percentage of encounters. Ringenberg and others ${ }^{16}$ found that $25.1 \%$ of NICU patients achieved serum trough levels between 10 and $20 \mathrm{mg} / \mathrm{L}$ with a commonly used empiric vancomycin regimen given in Neofax: A Manual of Drugs Used in Neonatal Care. ${ }^{17}$ Dersch-Mills and others ${ }^{18}$ evaluated a different empiric vancomycin regimen and found that only $34 \%$ of patients achieved a trough level between 10 to $20 \mathrm{mg} / \mathrm{L}$. In the study reported here, which used a simplified version of the Neofax regimen, $55 \%$ of trough levels fell between 10 and $20 \mathrm{mg} / \mathrm{L}$.

The target trough vancomycin levels associated with efficacy are not known for neonates. Determination of the target trough level should take into consideration the MIC of the organism being treated and the location and severity of the infection. ${ }^{47}$ In the current study, most of the patients with a positive culture result had organisms with MIC of $1 \mathrm{mg} / \mathrm{L}$ or less for vancomycin. Because most of the infections were bacteremia or sepsis-related, a trough level of 8 to $10 \mathrm{mg} / \mathrm{L}$ would be appropriate for the majority of these patients. The current empiric vancomycin regimen yielded acceptable trough levels for most of the patients. Therefore, for patients with organisms for which MIC is known, target vancomycin levels could be selected accordingly.

This study also evaluated the clinical significance of vancomycin levels in neonates, a topic that has not been addressed in previous studies. However, a limitation of this study was that the information about clinical status was collected retrospectively, and only $25(30 \%)$ of patient encounters had a documented change from baseline clinical status after initiation of vancomycin. The mean time to clinical resolution for these 25 patients was 6 days (range 2 to 17). Various studies have shown time to clinical resolution of 3 to 7 days in adults with community-acquired pneumonia. ${ }^{19-22}$ A study involving adults with sepsis and concurrent bacteremia showed a median time to clinical response of 2 or 4 days, depending on the type of blood culture identification test. ${ }^{23}$ Clinical resolution in the neonatal population may be delayed because the source of infection is not always removed once the infection has been diagnosed. For example, central lines or 
endotracheal tubes are often not removed until the patient has become clinically stable and can tolerate the necessary changes. No statistically significant correlation between vancomycin trough level and clinical resolution was found in this study. This finding may have been confounded by the small sample size, but it raises questions as to whether an increase in vancomycin levels increases efficacy and whether lower targets would be sufficient to achieve clinical resolution, while minimizing the risk of toxicity. With regard to microbiological cure, the collection of samples for repeat culture was at the discretion of the physician at the time of care; as such, the actual time to microbiological cure was not known and might have been earlier than what was found in this review, which would have been apparent only if culture samples had been collected earlier.

Lestner and others ${ }^{24}$ reported that the incidence of vancomycin nephrotoxicity in neonates was $1 \%$ to $9 \%$, similar to the overall incidence of nephrotoxicity in our study (5\%). A review by Bhargava and others ${ }^{25}$ evaluated the risk of acute kidney injury in NICU patients in relation to serum trough concentrations and showed that trough concentrations above $15 \mathrm{mg} / \mathrm{L}$ were associated with increased incidence of nephrotoxicity $(18.2 \%)$ relative to trough concentrations between 10 and $15 \mathrm{mg} / \mathrm{L}(0 \%)$ and less than $10 \mathrm{mg} / \mathrm{L}(1.4 \%)$. The current study had similar findings, in that the incidence of neonatal nephrotoxicity was higher with vancomycin trough levels above $15 \mathrm{mg} / \mathrm{L}(22 \%)$ relative to levels of $15 \mathrm{mg} / \mathrm{L}$ or less $(0 \%)$. However, it was difficult to determine whether the nephrotoxicity was a result of the vancomycin or other risk factors, including infection-related factors or concomitant nephrotoxins. Among the 4 patients with nephrotoxicity, the only additional risk factors identified were the use of concurrent gentamicin (for 3 patients) and septic shock requiring vasopressors (for 1 patient). Therefore, if trough vancomycin levels above $15 \mathrm{mg} / \mathrm{L}$ are targeted, it may be prudent to observe patients closely for signs and symptoms of nephrotoxicity and to assess, on a case-by-case basis, whether levels above $15 \mathrm{mg} / \mathrm{L}$ are truly needed.

Little appears to be known about the incidence of vancomycin-induced ototoxicity in neonates. Vancomycininduced ototoxicity has not been consistently shown in animal studies, and clinical studies suggest that apparent vancomycininduced ototoxicity may in fact be related to administration of impure fermented products and concomitant ototoxins. ${ }^{26}$ We did not evaluate vancomycin-induced ototoxicity in this study because of its rare occurrence and inconsistent results in the available literature.

\section{CONCLUSION}

The current Fraser Health empiric vancomycin regimen generated trough levels within the target range of 5 to $15 \mathrm{mg} / \mathrm{L}$ for most patients in this study. All of the patients received vancomycin for the treatment duration appropriate for their diagnosis, and the mean times to microbiological and clinical resolution were 5 and 6 days, respectively. Of concern was the fact that $22 \%$ of patients with vancomycin trough levels above $15 \mathrm{mg} / \mathrm{L}$ experienced nephrotoxicity. Additional studies evaluating the clinical significance of vancomycin levels in neonates are needed to help identify the preferred vancomycin target levels for this patient population and thereby to ensure efficacy and minimize toxicity.

\section{References}

1. Lessa FC, Edwards JR, Fridkin SK, Tenover FC, Horan TC, Gorwitz RJ Trends in incidence of late-onset methicillin-resistant Staphylococcus aureus infection in neonatal intensive care units: data from the National Nosocomia Infections Surveillance System, 1995-2004. Pediatr Infect Dis J. 2009; 28(7):577-81.

2. Muller-Pebody B, Johnson AP, Heath PT, Gilbert RE, Henderson KL, Sharland M; iCAP Group (Improving Antibiotic Prescribing in Primary Care). Empirical treatment of neonatal sepsis: are the guidelines adequate? Arch Dis Child Fetal Neonatal Educ. 2011;96(1):F4-F8.

3. Performance standards for antimicrobial susceptibility testing; twenty-fifth informational supplement. CLSI document M100-S25. Wayne (PA): Clinical and Laboratory Standards Institute; 2015.

4. Larsson AJ, Walker KJ, Raddatz JK, Rotschafer JC. The concentrationindependent effect of monoexponential and bioexponential decay in vancomycin concentrations on the killing of Staphylococcus aureus under aerobic and anaerobic conditions. J Antimicrob Chemother. 1996;38(4): 589-97.

5. Zimmermann AE, Katona BG, Plaisance KI. Association of vancomycin serum concentrations with outcomes in patients with gram-positive bacteremia. Pharmacotherapy. 1995;15(1):85-91.

6. Rybak MJ, Lomaestro BM, Rotschafer JC, Moellering RC, Craig WA, Billeter M, et al. Vancomycin therapeutic guidelines: a summary of consensus recommendations from the Infectious Diseases Society of America, the American Society of Health-System Pharmacists, and the Society of Infectious Diseases Pharmacists. Clin Infect Dis. 2009;49(3):325-7.

7. Moise-Broder PA, Forrest A, Birmingham MC, Schentag JJ. Pharmacodynamics of vancomycin and other antimicrobials in patients with Staphylococcus aureus lower respiratory tract infections. Clin Pharmacokinet. 2004;43(13):925-42.

8. Liu C, Bayer A, Cosgrove SE, Daum RS, Fridkin SK, Gorwitz RJ, et al Clinical practice guidelines by the Infectious Diseases Society of America for the treatment of methicillin-resistant Staphylococcus aureus infections in adults and children. Clin Infect Dis. 2011;52(3):e18-e55.

9. Chhim RF, Arnold SR, Lee KR. Vancomycin dosing practices, trough concentrations, and predicted area under the curve in children with suspected invasive staphylococcal infections. J Pediatric Infect Dis Soc. 2013;2(3): 259-62.

10. de Hoog M, Mouton JW, van de Anker JN. Vancomycin: pharmacokinetics and administration regimens in neonates. Clin Pharmacokinet. 2004;43(7): 417-40.

11. Rybak MJ, Cappelletty DM, Ruffing MJ, et al. Influence of vancomycin serum concentrations on the outcome of patients being treated for gram-positive infections [abstract]. In: Program and abstracts of the 37th Interscience Conference on Antimicrobial Agents and Chemotherapy; 1997 Sep 28 to 1997 Oct 1; Toronto (ON). Washington (DC): American Society for Microbiology; 1997. p. 9.

12. Rybak MJ, Akins RL. Emergence of methicillin-resistant Staphylococcus aureus with intermediate glycopeptide resistance: clinical significance and treatment options, Drugs. 2001;61(1):1-7.

13. Barriere SL, Stryjewski ME, Corey GR, Genter FC, Rubinstein E. Effect of vancomycin serum trough levels on outcomes in patients with nosocomial pneumonia due to Staphylococcus aureus: a retrospective, post hoc, subgroup analysis of phase 3 ATTAIN studies. BMC Infect Dis. 2014;14:183. 
This single copy is for your personal, non-commercial use only.

For permission to reprint multiple copies or to order presentation-ready copies for distribution, contact CHP at publications@cshp.pharmacy

14. Sawchuk RJ, Zaske DE, Cipolle RJ, Wargin WA, Strate RG. Kinetic model for gentamicin dosing with the use of individual patient parameters. Clin Pharmacol Ther. 1977;21(3):362-9.

15. Jetton JG, Askenazi DJ. Update on acute kidney injury in the neonate. Curr Opin Pediatr. 2012;24(2):191-6.

16. Ringenberg $T$, Robinson C, Meyers R, Degnan L, Shah P, Siu A. Achievement of therapeutic vancomycin trough serum concentrations with empiric dosing in neonatal intensive care unit patients. Pediatr Infect Dis J. 2015;34(7):742-7

17. Young TE, Mangum B. Neofax: a manual of drugs used in neonatal care. 23rd ed. Columbus (OH): Ross Laboratories; 2010.

18. Dersch-Mills D, Bengry T, Akierman A, Alshaikh B, Yusuf K. Assessment of initial vancomycin dosing in neonates. Paediatr Child Health. 2014;19(6): e30-4.

19. Halm EA, Fine MJ, Marrie TJ, Coley CM, Kapoor WN, Obrosky DS, et al. Time to clinical stability in patients hospitalized with communityacquired pneumonia: implications for practice guidelines. JAMA. 1998;279 (18):1452-7.

20. Douglas RM, Devitt L. Pneumonia in New Guinea. I. Bacteriological findings in 632 adults with particular reference to Haemophilus influenzae. Med J Aust. 1973;1(2):42-9.

21. Finkelstein MS, Petkun WM, Freedman ML, Antopol SC. Pneumococcal bacteremia in adults: age-dependent differences in presentation and in outcome. JAm Geriatr Soc. 1983;31(1):19-27.

22. Ortqvist A, Grepe A, Julander I, Kalin M. Bacteremic pneumococcal pneumonia in Sweden: clinical course and outcome and comparison with non-bacteremic pneumococcal and mycoplasmal pneumonias. Scand J Infect Dis. 1988;20(2):163-71.

23. Carreno JJ, Lomaestro BM, Jacobs AL, Meyer RE, Evans A, Montero CI. Assessment of time to clinical response in patients with sepsis treated before and after implementation of a matrix-assisted laser desorption ionization time-of-flight blood culture identification algorithm. Infect Control Hosp Epidemiol. 2016;37(8):916-23.
24. Lestner JM, Hill LF, Heath PT, Sharland M. Vancomycin toxicity in neonates: a review of the evidence. Curr Opin Infect Dis. 2016;29(3):237-47.

25. Bhargava V, Malloy M, Fonseca $\mathrm{R}$. The association between vancomycin trough concentrations and acute kidney injury in the neonatal intensive care unit. BMC Pediatr. 2017;17(1):50.

26. Vella-Brincat JW, Begg EJ, Robertshawe BJ, Lynn AM, Borrie TL, Darlow BA. Are gentamicin and/or vancomycin associated with ototoxicity in the neonate? A retrospective audit. Neonatology. 2011;100(2):186-93.

Ruthdol Ywaya, BSC(Pharm), ACPR, was, at the time of this study, a Pharmacy Resident with Lower Mainland Pharmacy Services.

Brandi Newby, BSc(Pharm), ACPR, is Coordinator with the Neonatal and Pediatric Pharmacy of Surrey Memorial Hospital, Surrey, British Columbia.

Competing interests: None declared.

\section{Address correspondence to:}

Brandi Newby

Surrey Memorial Hospital

Critical Care Tower, Room 2-602

13750 96th Avenue

Surrey BC V3V $1 Z 2$

e-mail: brandi.newby@fraserhealth.ca

Funding: None received.

\section{ON THE FRONT COVER}

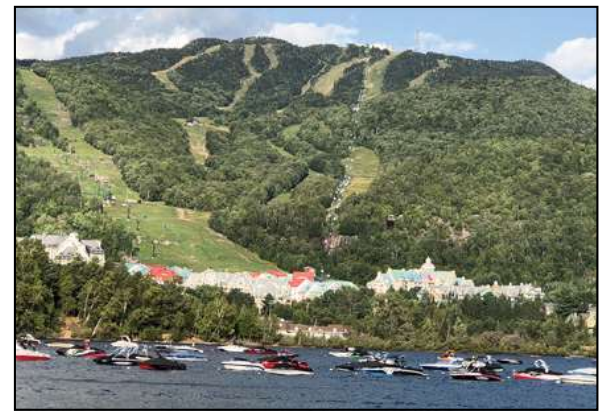

\section{Mont-Tremblant, Quebec}

This photograph of the Mont-Tremblant Ski Resort was taken from the pier on Lac Tremblant in August 2018. Helena Trabulsi was enjoying a scenic drive during her summer holiday and used an iPhone 8 s to capture the scene. Helena retired from her position as Director of Pharmacy with Halton Healthcare Services earlier that year.

The CJHP would be pleased to consider photographs featuring Canadian scenery taken by CSHP members for use on the front cover of the Journal. If you would like to submit a photograph, please send an electronic copy (minimum resolution $300 \mathrm{dpi}$ ) to publications@cshp.pharmacy. 